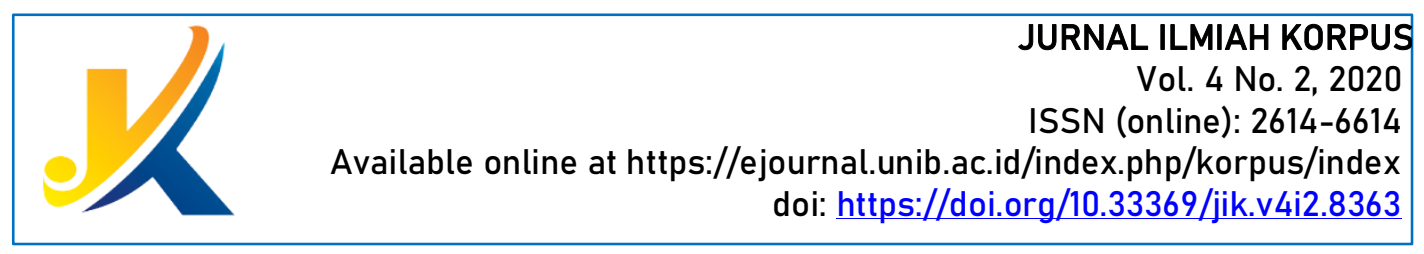

\title{
ASAL USUL CERITA BUTEU JUNG DI DESA RINDU HATI KECAMATAN TABA PENANJUNG KABUPATEN BENGKULU TENGAH
}

\author{
'Pebti Dita Wiriani; ${ }^{2}$ Amril Canrhas; ${ }^{3}$ Emi Agustina \\ 1,2,3 Program Studi Pendidikan Bahasa Indonesia FKIP Universitas Bengkulu
}

Abstrak

\section{Korespondensi: pebtiditawiriani18@gmail.com}

Tujuan penelitian ini yaitu (1) Mendeskripsikan cerita asal usul buteu jung di Desa Rindu Hati Kecamatan Taba Penanjung Kabupaten Bengkulu Tengah, (2) Mendeskripsikan fungsi cerita asal usul Buteu Jung di Desa Rindu Hati Kecamatan Taba Penanjung Kabupaten Bengkulu Tengah. Penelitian ini termasuk jenis penelitian kualitatif deskriptif yang menggambarkan fenomena yang terjadi pada objek apa adanya. Penelitian ini mengambil lokasi di Desa Rindu Hati Kecamatan Taba Penanjung Kabupaten Bengkulu Tengah. Data yang di peroleh adalah Cerita Asal Usul Buteu Jung dan Sumber Data di dapat dari 3 narasumber. Hasil penelitian ini adalah bahwa cerita asal usul buteu jung merupakan legenda, dan tergolong ke dalam legenda setempat. Dibuktikan dengan di dalam cerita terdapat cerita Desa Rindu Hati, Talang Kering, Tanah Patah, dan Taba Penanjung. Selain itu cerita ini berfungsi bagi masyarakat di bidang pendidikan.

Kata Kunci: asal usul, buteu jung, fungsi.

\section{Abstract}

The objectives of this study were (1) Describe the story of the origin of the buteu jung in Rindu Hati Village, Taba Penanjung District, Bengkulu Tengah District, (2) Describe the function of the story of the origin of Buteu Jung in Rindu Hati Village, Taba Penanjung District, Bengkulu Tengah Regency. This study includes a type of descriptive qualitative research that describes the phenomenon that occurs in objects as they are. This study took place in Rindu Hati Village, Taba Penanjung District, Bengkulu Tengah Regency. The data obtained is the Story of the Origin of Buteu Jung and Data Sources can be obtained from 3 speakers. The results of this study are that the story of the origin of the buteu jung is a legend, and belongs to local legend. It is proven by in the story there are stories of Rindu Hati Village, Talang Kering, Tanah Patah, and Taba Penanjung. In addition, this story functions for the community in the field of education.

Keywords: origin, buteu jung, function. 


\section{PENDAHULUAN}

Legenda adalah cerita prosa rakyat yang dianggap oleh yang empunya cerita sebagai suatu kejadian yang pernah terjadi. Legenda bersifat sekuler (keduniawian), terjadinya pada masa yang belum begitu lampau dan bertempat di dunia seperti yang kita kenal sekarang (Danandjaja, 1994:66).

Hampir di setiap daerah memiliki legenda tersendiri. Namun tidak menutup kemungkinan bahwa sekarang banyak cerita-cerita atau legenda yang sudah dilupakan, padahal legenda itu memiliki makna terhadap daerah tersebut. Salah satu daerah yang memiliki legenda namun sudah banyak yang tidak mengetahui adalah asal-usul cerita Buteu Jung di Desa Rindu Hati Kecamatan Taba Penanjung Kabupaten Bengkulu Tengah. Cerita ini memiliki fungsi atau makna bagi masyarakat di Desa Rindu Hati namun hanya beberapa masyarakat saja yang mengetahui cerita ini. Ditakutkan nantinya cerita ini akan hilang atau dilupakan. Oleh karena itu, asal-usul cerita Buteu Jung ini perlu untuk diteliti agar cerita ini tidak dilupakan dan tetap dipertahankan, selain itu legenda ini diharapkan dapat dikenal lebih banyak orang lagi, bukan hanya masyarakat yang berusia lanjut dan hanya beberapa orang saja yang mengetahui tetapi lebih banyak lagi masyarakat yang mengetahui terutama masyarakat Desa Rindu Hati.

Legenda ini termasuk ke dalam legenda setempat. Legenda setempat adalah cerita yang berhubungan dengan suatu tempat, nama tempat, dan bentuk topografi, yakni bentuk permukaan suatu daerah, apakah berbukit-bukit, berjurang dan sebagainya (dalam Andalas, 2017: 45). Menurut Alex Olrik (dalam Danandjaja, 1994:82-83) struktur atau susunan cerita prosa rakyat terkait oleh hukum-hukum yang sama, yang olehnya disebut sebagai "hukum-hukum epos(epic laws)". Hukum-hukum epos ini merupakan sesuatu yang berada di atas cerita-cerita rakyat, yang selalu mengendalikan para juru ceritanya (folk narrators), sehingga mereka hanya dapat mematuhi hukum-hukum itu secara membuta.

Adapun fungsi di dalam Cerita rakyat yaitu: (1) Menghibur, suatu karya sastra yang diciptakan berdasarkan keinginan melahirkan suatu rangkaian berbahasa yang indah dan bunyi yang merdu, (2) Mendidik, sastra dapat memberikan pelajaran tentang kehidupan. Teori fungsi berkaitan dengan manfaat atau guna dari cerita tersebut. Teori fungsi tersebut merupakan sesuatu hal yang bermanfaat bagi manusia dalam kebudayaan tertentu. Manfaat dalam sebuah karya sastra atau pun sebuah cerita prosa berkaitan dengan sesuatu yang menyenangkan (utile) dan berguna (dulce) bagi kehidupan masyarakat (Wellek dan Warren, 1990:21).

Berbicara fungsi folklor menurut Bascom (dalam Endraswara, 2009:128) tidak dapat dilepaskan begitu saja dari kebudayaan secara luas, dan juga dengan konteksnya. Manfaat tersebut ada yang bermanfaat secara pribadi, sosial serta dalam bidang kebudayaan bagi etnik tertentu, disebut adanya kebenaran universal bagi kemanusiaan menurut (Teeuw, 2013:28). Folklor memiliki seseorang dapat dimengerti sepenuhnya hanya melalui pengetahuan yang mendalam dari kebudayaan orang yang memilikinya.

Artikel ini juga bermanfaat untuk membantu para peminatn dan pemerhati sastra untuk mengkaji lebih lanjut, khususnya asal-usul cerita Buteu Jung, mmenjadi sumbangan dalam rangka inventari, pembinaan, pelestarian, dan pengembangan sastra, dan dapat menjadi referensi atau masukan bagi guru-guru menjadikan cerita sebagai bahan ajar.

Artikel ini akan mendeskripsikan asal-usul cerita Buteu Jung dan mendeskripsikan fungsi asal-usul cerita Buteu Jung. 


\section{METODE}

Metode yang digunakan dalam penelitian ini adalah metode deskriptif. Metode deskriptif merupakan metode yang dilakukan dengan tidak menggunakan angka-angka, tetapi menggunakan penghayatan terhadap interaksi antar konsep yang sedang dikaji secara empiris. Berdasarkan metode penelitian folklor di atas, maka dalam penelitian ini akan dideskripsikan isi cerita dan fungsi cerita asal usul Buteu Jung di desa Rindu Hati Kecamatan Taba Penanjung Kabupaten Bengkulu Tengah.

Adapun Data dalam penelitian ini berupa cerita Asal Usul Buteu Jung di Desa Rindu Hati Kecamatan Taba Penanjung Kabupaten Bengkulu Tengah. Sedangkan sumber data dalam penelitian ini adalah dari informan, dalam bentuk wawancara pada informan, video, dan foto cerita asal usul Buteu Jung di Desa Rindu Hati Kecamatan Taba Penanjung Kabupaten Bengkulu Tengah.

Dalam penelitian ini peneliti juga menggunakan syarat informan Menurut Spradley (dalam Iskandar, 2009:116-117), berupa, mereka yang menguasai atau memahami masalah yang diteliti, mereka yang sedang berkecimpung atau terlibat pada kegiatan yang sedang diteliti, mereka yang mempunyai waktu yang memadai untuk diminta informasi, mereka yang tidak cenderung menyampaikan informasi hasil kemasannya, masyarakat yang paham atau benar-benar tahu tentang cerita, masyarakat asli desa Rindu hati, dan berusia 50-70an tahun.

Adapun teknik pengumpulan data dalam penelitian ini yaitu: (1)Teknik Rekaman. Teknik ini menggunakan kamera untuk dokumentasi foto dan telepon genggam untuk merekam narasumber saat wawancara.(2)Teknik Wawancara. Wawancara ialah proses komunikasi atau interaksi untuk mengumpulkan informasi dengan menganalisis data pada penelitian ini pertama melakukan transkrip cerita. Data yang diperoleh dari rekaman disalin dalam bentuk bahasa asli narasumber yaitu bahasa Rejang. Selanjutnya yang kedua yaitu menerjemahkan data hasil transkrip cerita dari bahasa Rejang menjadi bahasa Indonesia agar lebih mudah dipahami. Langkah ketiga adalah analisis cerita dan fungsi cerita.

\section{HASIL DAN PEMBAHASAN}

Pada cerita asal usul Buteu jung peneliti mewawancarai tiga narasumber dan dari hasil wawancara itu peneliti menemukan tiga cerita mengenai Asal Usul Buteu Jung di Desa Rindu Hati Kecamatan Taba Penanjung Kabupaten Bengkulu Tengah yang sedikit berbeda informasinya dari setiap narasumber namun tetap memiliki inti cerita yang sama. Maka peneliti membagi cerita menjadi tiga versi. Ketiga versi itu adalah : cerita versi Bapak Ramuhin (ketua adat), cerita versi Bapak Sultan Mukhlis (Kepala Desa), dan cerita versi Bapak Jo (Sekdes). berawal dari adanya kerajaan Sungai Lemau, yang di mana kerajaan ini dipimpin oleh Anak Dalam Muaro Bangka Hulu. Anak Dalam Muaro Bangka Hulu ini terdiri dari 8 bersaudara.

"Kerajaan Sungai Lemau dipimpin ngen Anak Dalem, si o biade delapen basoak, pertamo ne gen ne Ci Putri, si tun ne abli dalem sastra si pacak ngecek men nadeak tun uyo. Wateu Ci Putri ngen Putri Gading Cempaka tecenulik ngen Rajo Aceh, si madeak ngen kerajaan o sesuai ngen kemampuan ngecek ne, untuk melaksano lamaran o tojoak bilei tojoak malem, padahal maksud si o gulur wakteu sapei soak basoak ne tenapet si beduei nak kerajaan o". 


\section{Pebti Dita Wiriani; Amril Canrhas; Emi Agustina}

Pada suatu hari Raja Aceh datang ke kerajaan Sungai lemau untuk melamar Putri Gading Cempaka untuk dinikahi dengan anak Raja Aceh yang merupakan seorang Pangeran. Namun Anak Dalam sebagai seorang kakak tidak bisa langsung saja menerima, karena dia mengetahui bagaimana Raja Aceh tersebut. Anak Dalam sangat melindungi adiknya, dan dalam perjodohan sebelumnya ia menanyakan terlebih dahulu kepada adik bungsunya yang sangat dia sayangi itu, akan tetapi Putri Gading Cempaka tidak menerima lamaran dari Raja Aceh.

Raja Aceh tersinggung dengan keputusan Putri Gading Cempaka karena menolak lamaran Raja Aceh untuk anaknya. Maka Anak Dalam membuat syarat-syarat tertentu untuk di penuhi oleh Raja Aceh agar lamarannya bisa di terima. Anak Dalam tidak meminta apapun dalam bentuk emas ataupun uang. Tetapi dia hanya meminta empat hal yang dapat dilakukan oleh Raja Aceh. Permintaan itu berupa yang pertama atan ditanam bisa tumbuh atau hidup, lalu yang kedua Kemiri ditanam tumbuh dalam waktu 7 hari, ketiga kayu di potong atau ditebang akan tumbuh cendawan putih dan permintaan terakhir ke empat daun sirih dapat tumbuh di kandang kuda.

"mangko dek tetuei asoak basoak Putri Gading Cempaka, tuei sekilei Anak Dalam si coa madek pengerak penginai. Si bekinai men dapet kenabul ne si melaksanaken pernikahan 0. Si coa kinai mas coa kinai taci coa kinai jano-jano Cuma si bekinai pertamo ne utuk betune, yang keduei ne si bekinai nanem mingai tojoak bilei temuak, yang ketleu si bekinai kioa idup tentok, temuat ti'ua puteak, udem o si bekinai terakbir iben temoat nak kanang kudo".

Namun karena Raja Aceh merasa tidak sanggup memenuhi permintaan yang mustahil bisa ditepati ia memutuskan untuk pulang dan tidak bisa mengabulkan permintaan yang di ajukan oleh Anak Dalam. Saat dalam perjalanan pulang ke Aceh, Raja Aceh merasa sangat malu dan dilecehkan, akhirnya ia langsung memikirkan untuk menculik Putri Gading Cempaka. Raja langsung menyusun rencana dan mengutuskan orang-orang yang ada di kerajaannya untuk menculik Putri Gading Cempaka.

Akhirnya rencana penculikan itu berhasil dilakukan, Raja Aceh berhasil menculik Putri Gading Cempaka bersama dengan Dayang Perindu, karena Dayang Perindu memang bersama Putri Gading Cempaka. Sesampainya di dalam kerajaan Aceh, sang Rajapun langsung menyusun strategi untuk melaksanakan pesta pernikahan. Namun karena Dayang Perindu merupakan orang yang pintar berbicara, maka dia berhasil membuat Raja Aceh untuk membuat acara pernikahan itu resmi setelah tujuh hari tujuh malam. Dayang perindu mampu meyakinkan sang raja, yang sebenarnya niat Dayang Perindu melakukan negosiasi itu hanya untuk mengulur waktu sampai saudarasaudaranya datang untuk menjemput mereka.

Saat hari ketujuh itu telah tiba, Raja Aceh langsung menyebarkan kabar bahwa beliau akan melaksanakan pesta pernikahan anaknya dengan Putri Gading Cempaka. Selain itu Raja Aceh juga mengumpulkan orang-orang yang merupakan prajurit istana dan saudara-saudaranya yang merupakan orang-orang hebat atau orang-orang yang sakti, karena Raja Aceh takut akan ada yang merusak pesta yang akan dia laksanakan.

"Raja Aceah cenulik Putri Gading Cempaka ngen Ci Putri si min nak kerajaan ne nak. Aceah. Karno Ci Putri meraso kaleu asoak basoak ne bi teu dan tobo o bi udem tenusun rencano untuk selamat ke tobo o, jijei Ci Putri bi madeak ngen Rajo Aceab kaleu acara o 
nuleak dilaksano bi udem tojoak bilei. Pas bilei ke tojoak tnebar ba Rajo Aceah yo ngen asoak basoak, masyarakat ngen tun-tun beilmeu nak penan si o, kaleu-kaleu ade tun lak ngaceah acarao. Ternyato rombongan Anak. Dalam bi merencano ke kulo lak napet asoak si, cak ipepun ca'o ne, perang si bi siap perang".

Ternyata selain Kerajaan Aceh yang sudah menyusun rencana untuk melakukan pesta pernikahan antara Putri Gading Cempaka dengan Pangeran yang merupakan Anak dari Raja Aceh. Kerajaan Sungai Lemau juga telah menyiapkan strategi untuk menyelamatkan Putri Gading Cempaka dengan Ci Putri untuk di bawa pulang ke kerajaan.

Anak Dalam memerintahkan tugas kepada Monok Micur dan Selendang Papan untuk pergi ke Aceh melihat kondisi saudaranya dan mengetahui apa yang akan direncanakan oleh kerajaan Aceh. Alasan dari Anak Dalam memerintahkan Monok Micur dan Selendang Papan karena kesaktian yang dimiliki mereka bisa digunakan untuk mengintai.

"Anak Dalem o meriteak ba mai Aceah o Monok. Micur ngen Selendang Papan. Karno si beduei o teu jjei jano-jano, Monok Micur pacak jijei hewan, kaleu Selendang Papan teu terbang. Sapei nak Kerajaan Aceah o beubeak ba Monok Micur uyo jijei kucing, mangko si pacak mesuk mai bilik Ci Putri ngen Putri Gading Cempaka. Si semelidik kileak nadeak ne, uyo udi siap-siap karno uyo bi tojoak bilei tojoak malem. Malem ketojoak keme temot ko minai menapet, jijei belek mekuleu. Udem o si belek mai kuleu melapor ngen Anak Dalem kaleu tobo o melaksno tojoak bilei. Malem ke tojoak.jam 12 malem ite berakat ka'te menapet ne mai Aceah."

Akhirnya Putri Gading Cempaka berhasil di bawa kembali ke kerajaan Sungai Lemau di Bengkulu. Namun, Anak Dalam Muaro Bangka hulu telah memikirkan bahwa, Raja Aceh pasti akan marah besar dan membuat sebuah penyerangan peperangan. Lalu ia memerintahkan kembali Selendang Papan untuk melihat apa yang akan dilakukan oleh Raja Aceh. Saat melakukan pengintaian Selendang Papan berubah lagi menjadi hewan yang tidak akan dicurigai sampai dia mendapatkan susunan yang akan dilakukan oleh Raja Aceh untuk menyerang ke Kerajaan Sungai Lemau.

"Udem o Rajo Aceah yo coa mungkin coa manes, si pasti tenusun rencano peperangan. Udem o Anak Dalam tenutus Selendang Papan yo kemeleak kerajaan Aceab o cak ipe keputusan ne. Sapei mai Aceah si berubeak, jijei tu'eusi lak semedi oba coa ba tun pedulei. Na dapet ba si keputusan ne Aceah lak kemajak mekuleu tun sakti o beraket ka'te, udem o tenulung kulo min minyak, selupur nyawa, minyak o pacak. kaleu tun matei bi idup igei oba guno ne minyak. o. Tenengoa berita o Selendang Papan yo ano melapor ba igei ngen Anak Dalam”.

Peperangan yang terjadi, merupakan peperangan yang besar-besaran. Kerajaan Aceh telah membagi menjadi 3 tim penyerangan dan berbeda-beda lokasi. Lalu dari pihak Kerajaan Sungai Lemau juga sudah menyiapkan strategi pertahanan dan siap menyerang. Karena sang kakak yang merupakan Raja dalam Kerajaan Sungai Lemau yaitu Anak Dalam, merasa bahwa sang adik tidak akan aman jika tetap berada di dalam kerajaan. Akhirnya dia mengutuskan untuk melarikan adiknya dari kerajaan. Ia memerintahkan 


\section{Pebti Dita Wiriani; Amril Canrhas; Emi Agustina}

Lemang Batu untuk membuat kapal atau yang disebut Jung untuk di naiki oleh Putri Gading Cempaka dan Ci Putri atau Dayang Perindu. Dan untuk mengarahkan kapal itu dia juga meminta kepada Kelam Muaro untuk menerbangkan kapal itu ke Sungai Muara Bangka Hulu sampai ke Sungai Rindu Hati.

"jijei si kepekea cak ipe akal ne si pacak munyin selawei ne Putri Gading Cempaka o. Menok ba si mai Lemang Buteu Menea Buteu Jijei kapal atau Jung. Udem Putri Gading Cempaka ngen Ci Putri menek nak Jung si meriteak. Kelam Muaro tenebang Jung o nak bioa kuleu sapei nak. duatei."

Setelah mengasingkan Putri Gading Cempaka mereka langsung melakukan peperangan melawan Kerajaan Aceh. Dalam cerita peperangan ini terdapat pula cerita asal usul nama-nama daerah lainnya, seperti Pekik Nyaring, Tanah Patah, Talang Kering, dan Taba Penanjung.

Berdasarkan wawancara yang telah dilakukan dengan narasumber yaitu Bapak Ramuhin peneliti menemukan asal usul Buteu Jung atau Batu Jung berasal dari batu yang dibuat oleh lemang batu menjadi sebuah kapal atau menjadi Jung, bukan kapal atau Jung yang berubah menjadi batu. Dalam hasil wawancara ini, peneliti mendapatkan bahwa dari cerita lebih di tekankan asal-usul desa Rindu Hati.

Hal ini dikarenakan pada saat akhir dari cerita dimana saat peperangan sudah selesai dan keenam saudara Putri Gading Cempaka ingin menjemput Putri Gading Cempaka dan Ci Putri untuk kembali kerajaan. Namun, saat mereka sampai di sungai tempat Putri Gading Cempaka dan Ci Putri berlindung, Ci Putri ternyata tidak ingin kembali ke kerajaan karena ia telah terpikat dengan siluman yang ada di sana, akhirnya yang kembali hanya keenam saudara dan Putri Gading Cempaka saja, sedangkan Ci Putri tetap tinggal di sana. Karena ketujuh saudara ini tadi merasa rindu dan masih ingin merayu Ci putri untuk kembali ke kerajaan kembali lagi mereka ke keberadaan Ci Putri namun alhasil sama saja, Ci Putri tetap ingin tinggal di sana. Singkat cerita akhirnya mereka membuat desa si tempat Ci Putri karena merasakan kerinduan dari saudara-saudaranya diberilah nama desa itu Rindu Hati. Namun nama awal daerah itu adalah tslsng musro lalu diganti menjadi deu atei dan ndu atei (dalam bahasa rejang), dan terakhir berubah menjadi Rindu Hati sampai saat ini.

Berdasarkan hasil wawancara dari ketiga narasumber, adapun analisis yang dapat ditemukan, yaitu:

Dari cerita tersebut peneliti mengetahui bahwa cerita asal usul buteu jung ini merupakan sebuah legenda. Karena legenda merupakan cerita prosa rakyat yang dianggap oleh yang empunya cerita sebagai suatu kejadian yang sungguh-sungguh pernah terjadi. Seperti yang dikatakan oleh narasumber bahwa mereka benar-benar mempercayai adanya cerita ini dengan bukti keberadaan batu jung. Cerita ini juga dipercayai karena menurut warga dahulu tali pengikat kapal itu masih ada dan berbentuk ijuk yang sangat tebal dan panjang, yang suatu saat berubah menjadi ular yang sangat besar. Namun disayangkan sekarang tali yang dipercayai oleh warga itu sudah tidak ada lagi, menurut kesaksian mereka sudah hilang. Seperti yang di jelaskan oleh Bapak Ramuhin.

"Beloo Jung o ade tilei pengeket ne, tilei o jak ijuk cuman si o pacak beubeak jïjei nopoi ley. Cuman uyo ba si o laput coa ade igei coa nam nak ipe penan ne." 
Dari ucapan Bapak Ramuhin yang mengatakan, bahwa dahulu kala perahu atau Jung itu di ikat oleh sebuah tali yang terbentuk dari sebuah ijuk kemudian dapat berubah menjadi seekor ular yang sangat besar. Namun sekarang tali itu sudah hilang tidak diketahui lagi dimana keberadaannya. Adapun ungkapan Bapak Ramuhin yang mengatakan bahwa Dayang Perindu atau Ci Putri masih ada di daerah sana.

"Ci Putri o bi ade nak bukit Ndeu o, jïjei kaleu bi ade tun besilek, mai uyo, kaleu bilei malem si o pacak be tu'un mai tun latian silek o. Si pacak kulo mileu tun besilek o."

Dari penjelasan Bapak Ramuhin yang mengatakan bahwa keberadaan Ci Putri atau Dayang Perindu masih ada di sana, dengan dibuktikannya ketika warga atau perguruan silat yang ada di Desa sedang melakukan latihan atau ujian pada malam hari, Ci Putri pernah datang dan menjelma atau merasuki salah satu dari anak silat yang sedang berlatih.

Dari cerita ini juga peneliti dapat mengetahui jenis dari legenda cerita ini termasuk ke dalam legenda setempat. Hal ini dibuktikan dengan cerita dari narasumber yang menjelaskan bahwa penamaan nama-nama desa atau daerah dari cerita yang ada di dalam cerita Buteu Jung.

"karno raso ineu soak basuak Putri Gading Cempaka uyo ano ngen Ci Putri. Ci Putri Coa lak belek igei mai kerajaan karno si bi tepeket nen siluman nak di. Oba karno ineu o soak basoka Putri yo ano ngen sadei o gen ne sadei Ndu Atei, atau tun uyo nadeak ne Rindu Hati."

Dari kutipan tersebut Bapak Ramuhin menjelaskan bahwa nama Desa Rindu Hati terbentuk dari dalam cerita Asal Usul Buteu Jung. Hal ini dikarenakan kerinduan yang dirasakan oleh Putri Gading Cempaka dan saudara-saudaranya kepada Ci Putri yang sudah memutuskan untuk tetap tinggal di tempat dimana Putri Gading Cempaka di asingkan saat peperangan antara Kerajaan Sungai Lemau dan Kerajaan Aceh. Karena rasa rindu yang mendalam dirasakan oleh mereka, maka Anak Dalam memutuskan membagi wilayah terhadap saudara-saudaranya dan sebagian menemani Ci Putri tinggal di wilayah itu dan memberi nama wilayah atau desa itu dengan nama Rindu Hati.

Selain desa Rindu Hati terdapat pula nama-nama wilayah lain yang terdapat di dalam cerita. Seperti penamaan Kecamatan Taba Penanjung, yang berasal dari cerita pada saat Anak Dalam dan semua saudara laki-lakinya yang mencari keberadaan Buteu Jung atau Jung yang di kendarai oleh Ci Putri dan Putri Gading Cempaka. Namun saat pencarian, jawaban oleh masyarakat adalah 'Taba Penan Jung' yang dalam artian adalah 'Taba' berarti entahlah, sedangkan 'Penan' yang berarti tempat, dan 'Jung' yang berarti kapal atau perahu. Dari sinilah daerah wilayah Taba Penanjung terbentuk. Hal ini terdapat dalam ungkapan Bapak Ramuhin.

"wakteu Anak Dalam ngen asoak basoak uyo ano mesoa keberadaan Putri Gading Cempaka ngen Ci Putri, tobo o tenanye ngen tu nak ipo penan Buteu Jung, bi ade keten coa. Oba nadeak tun belo'o taba penan jung. Karno o ba daerah uyo bi namo ne Taba Penanjung". 


\section{Pebti Dita Wiriani; Amril Canrhas; Emi Agustina}

Kemudian terdapat penamaan Tanah Patah, Talang Kering, dan Pekik Nyaring. Menurut Bapak Ramuhin nama daerah Tanah Patah terbentuk saat lompatan yang dilakukan oleh Lemang Batu.

"Lemang Buteu tenengoa pekikan Anak. Dalam o sserentak, ba si tejun nak, taneak o serentak. libea oba tun nadeak ne Tanah Patah."

Menurut penjelasan bapak Ramuhin, saat Lemang Batu mendengar isyarat yang di berikan oleh Anak Dalam, ia langsung terjun sehingga serentak wilayah itu menjadi retak dan patah, sehingga di berilah nama menjadi Tanah Patah, tanah patah ini berawal dari lompatan yang dilakukan oleh Lemang Batu.

"wakteu peperangan Anak Dalam uyo ano tenengoa beriteak kaleu tun Aceab o bi ade paak. tapen Cuma si coa keten kaleu bi ade, karno seunt nenien, oba krno tobo o coa keten, kemibar ba ngen Anak Dalam uyo ano keis si, oba abis kate tun nak. Aceab o krn kesaktian keis Anak Dalam. Sisone be tulang-belulang tu Aceah nak di o. Oba tun nadeak sadei ne Talang Kering.”

Dari beberapa penjelasan mengenai penamaan-penamaan tempat atau wilayah desa yang ada di dalam cerita buteu jung yang diucapkan oleh Bapak Ramuhin saat wawancara, maka peneliti mengetahui bahwa asal usul buteu jung termasuk ke dalam legenda setempat. Legenda setempat merupakan legenda yang menceritakan penamaanpenamaan suatu tempat atau wilayah.

Namun dari ketiga cerita yang diperoleh dari ketiga narasumber maka dapat di ketahui bahwa Buteu Jung atau Batu Perahu berasal dari buatan Lemang Batu atau Umang Batu yang menggunakan kesaktiannya yang dapat mengubah batu sesuai apa yang d inginkan, seperti yang di ucapkan oleh Bapak Ramuhin

"jijei si kepekea cak ipe akal ne si pacak munyin selawei ne Putri Gading Cempaka o. Menok ba si mai Lemang Buteu Menea Buteu Jijei kapal atau Jung. Udem Putri Gading Cempaka ngen Ci Putri menek nak. Jung si meriteak. Kelam Muaro tenebang Jung o nak bioa kuleu sapei nak duatei."

Bapak Ramuhin menjelaskan bahwa Anak Dalam terpikirkan bahwa bagaimana cara agar ia dapat menyembunyikan adiknya Putri Gading Cempaka agar tidak diambil lagi oleh Raja Aceh. Lalu dia meminta kepada Lemang Batu untuk membuat kapal atau perahu agar bisa digunakan oleh adiknya untuk lari dari Kerajaan. Setelah itu dibuatlah oleh Lemang Batu sebuah Kapal dari batu yang sekarang disebut Batu Jung. Selain itu menurut bapak Mukhlis juga mengatakan bahwa Batu Jung berasal dari buatan Lemang Batu saat hendak melarikan Putri Gading Cempaka dari kerajaan.

\section{PENUTUP}

Berdasarkan uraian dan pembahasan di atas dapat disimpulkan bahwa:

1. Cerita Asal Usul Buteu Jung merupakan legenda yang ada di Desa rindu Hati. Cerita Asal Usul Buteu Jung berawal dari sebuah cerita Kerajaan Sungai Lemau yang berperang dengan Kerajaan Aceh. Batu Jung tercipta dari dalam cerita bahwa Adanya 
permintaan Anak Dalam kepada Lemang Batu untuk membuatkan sebuah perahu yang akan di gunakan oleh adiknya nanti Putri Gading Cempaka untuk diungsikan sementara dari kerajaan, oleh karena itu dibuatlah oleh Lemang Batu sebuah perahu atau Jung yang terbuat dari batu karena itulah dinamakan Batu Jung atau Buteu Jung. Di dalam cerita Butue Jung juga terdapat cerita lagi seperti penamaan Desa Rindu Hati, Tanah Patah, Taba Penanjung, Pekik Nyaring dan lain-lain.

2. Fungsi dari Asal Usul Cerita Buteu Jung bagi masyarakat Desa Rindu Hati adalah mendidik, seperti pada cerita Anak Dalam yang mengajarkan kepada adik-adiknya bagaimana peduli sesama bersaudara, dan mengajarkan kesopanan saat menolak keinginan seseorang agar tidak mengecewakan perasaan orang tersebut. Fungsi lainnya di bidang pendidikan yang dapat digunakan guru saat mengajar materi cerita rakyat atau legenda, maka cerita ini dapat dijadikan bahan materi bahkan bisa dijadikan sebagai naskah drama.

Berdasarkan uraian dan pembahasan di atas terdapat beberapa saran yaitu:

1. Setelah peneliti melakukan penelitian di lapangan mengenai cerita legenda Buteu Jung dengan melakukan wawancara kepada narasumber-narasumber yang mengetahui cerita, terdapat perbedaan-perbedaan versi cerita oleh setiap masing-masing narasumber. Perbedaan sangat terlihat saat asal dari Buteu Jung atau Batu Jung itu, selain itu juga sosok seorang Dayang Perindu juga berbeda-beda dari berbagai narasumber. Mengenai hal ini peneliti mengemukakan saran kepada peneliti berikutnya agar dapat meneliti perbedaan cerita atau membandingkan cerita dari narasumber.

2. Dari hasil penelitian ini peneliti mendapat cerita-cerita lainnya dari dalam cerita Buteu Jung namun tidak secara mendalam. Peneliti mengharapkan kepada peneliti selanjutnya untuk meneliti cerita-cerita di dalam cerita Buteu Jung ini lebih mendalam lagi.

\section{DAFTAR PUSTAKA}

Andalas, Eggy Fajar \& Sulistyorini, Dwi. 2017. Sastra Lisan. Malang: Madani Kelompok Publishing.

Danandjaja, James. 1994. Folkor Indonesia Ilmu Gosip, Dongeng, dan Lain-lain. Jakarta: PT Pustaka Grafiti.

Endraswara, Suwardi. 2009. Metodologi Penelitian Folklor Konsep, Teori, dan Aplikasi. Yogyakarta: Madpress(Anggota IKAPI).

Teeuw, A. 2013. Sastra dan Ilmu Sastra. Bandung: PT. Dunia Pustaka Jaya

Wellek, Rene da Austin Warren. 1989. Teori Kesusastraan. Jakarta: Gramedia Pustaka Jaya 